\section{Urologia \\ Internationalis}

\section{Hussein Ghanem $^{\mathrm{a}}$ \\ Rany Shamloul ${ }^{a, b}$}

${ }^{a}$ Andrology and Sexology Department, Cairo University, Cairo, Egypt;

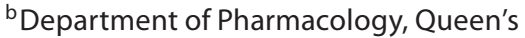

University, Kingston, Ont., Canada
Urol Int 2009;82:125-129

DOI: $10.1159 / 000200785$

\title{
An Evidence-Based Perspective to the Medical Treatment of Male Infertility: A Short Review
}

\section{Key Words}

Male infertility • Evidence-based medicine •

Follicle-stimulating hormone

\section{Abstract}

Introduction: Evidence-based medicine (EBM) is the integration of best research evidence with clinical expertise and patient preferences and values. Aim: This narrative review aims to assist the physicians to make informed decisions based on the best available evidence in the area of male infertility and the patients' own preferences and values. Methods: In this review we present the current state of knowledge and uncertainties about the medical management of male infertility. We describe the best available evidence from systematic reviews, randomized controlled studies and observational studies where appropriate. Results: Data from the literature suggest that gonadotropin treatment of male infertility can lead to a significant increase in pregnancy rates, however larger studies are needed to confirm such findings. Studies including combinations of antiestrogens, antioxidants and androgens are promising but need confirmation with further research. Conclusions: Most current combination therapies consist of orphan medications without industry support. Andrology research centers and other dedicated departments and units need to conduct randomized controlled trials of sufficient duration, sample number and robust design for groups most likely to benefit from antiestrogens, L-carnitine, antioxidants, and combination therapy. The ease of administration, low cost and mild side ef- fects of antiestrogens justify their utility despite insufficient evidence of effect as monotherapies. Randomized controlled trials assessing other forms of medical therapy and combination therapy are available but are still in the preliminary stages.

Copyright $\odot 2009$ S. Karger AG, Basel

\section{Introduction}

Evidence-based medicine (EBM) is an approach to answering clinical questions based on the integration of best research evidence with clinical expertise as well as patient preferences and values. Clinical judgment must then be used in deciding how to apply the evidence to each and every patient individually [1]. Medical research comprises studies that are either analytic or descriptive. Analytic studies encompass experimental studies that are either randomized controlled trials (RCTs) or nonRCTs, and observational reports that include cohort (prospective), case-control (retrospective), and cross-sectional studies. Descriptive studies include case series, case reports, and prevalence studies. The highest level of research evidence is obtained from meta-analyses of systematic reviews and RCTs. These are followed by observational studies, descriptive studies and expert opinion.

Medical literature reports medicaments for male infertility that fall into two main categories: specific and non-specific. Specific treatments are directed towards hypogonadotrophic hypogonadism, urogenital infec-

\section{KARGER}

Fax +4161306 1234

E-Mail karger@karger.ch

www.karger.com
(C) 2009 S. Karger AG, Basel

0042-1138/09/0822-0125\$26.00/0

Accessible online at:

www.karger.com/uin
Rany Shamloul

Department of Pharmacology, Queen's University

Kingston, Ont. K7L 3N6 (Canada)

Tel. +1 613533 6432, Fax +1 6135336412

E-Mail rannone74@hotmail.com 
tions, antisperm antibodies, and retrograde ejaculation. Among these, therapy for hypogonadotrophic hypogonadism is considered the most successful [2].

Non-specific treatments include antiestrogens, aromatase inhibitors, gonadotrophins, L-carnitine, antioxidants, vitamins, kallikrein, indomethacin, pentoxifylline, low-dose corticosteroids, androgens, and zinc. The question is: Does non-specific medical therapy for idiopathic male infertility work?

In this narrative review, we address the commonly used non-specific medications and assess the evidence for their utility in the management of idiopathic male infertility. Our aim is to assist physicians in counseling their patients to choose the most suitable treatment from among more valid therapeutic options, and still meet the couple's preferences and values.

\section{Gonadotropin Therapy}

The best available evidence concerning follicle-stimulating hormone (FSH) therapy includes a meta-analysis and its update published on the Cochrane Database $[2,3]$. It reported a significantly higher pregnancy rate $-13.4 \%$ (19 out of 142 couples in the study group) versus $4.4 \%$ (6 out of 136 couples in the control group) - following 3 months of FSH therapy in 278 participants (odds ratio 4.17, 95\% CI 1.30-7.09). The authors suggested further research to confirm these findings. Unfortunately, FSH therapy is relatively costly and involves repeated injections which may reflect on patient preference and compliance. Several other researchers $[4,5]$ tried to treat male infertility with FSH in unselected patients, however none reported increased pregnancy rates. Therefore, FSH therapy cannot be recommended in unselected men.

\section{Androgen Therapy}

Endogenous testosterone has central effects in the regulation of spermatogenesis. However, exogenous testosterone could lead to negative feedback inhibition of the pituitary and inhibit spermatogenesis. It is poorly taken up after oral administration. It is given parenterally as either short-acting testosterone phenyl propionate or long-acting testosterone enanthate or a mixture of several esters. A number of publications have suggested potential favorable effects on semen quality after testosterone administration [6-8], however the only positive effect actually observed in a randomized controlled study, regardless of the type of synthetic androgen used, was a moderate increase of the percentage of live spermatozoa [9]. No positive effect was noted on sperm morphology, concentration or motility.

\section{Antiestrogen Therapy}

Before the introduction of intracytoplasmic sperm injection (ICSI) and EBM, treatment options for idiopathic male factor subfertility were mainly based on antiestrogens. Antiestrogen therapy has been popular due to the low cost, safety and ease of administration.

A meta-analysis and its update [10] included 738 subfertile males with oligoasthenozoospermia exposed to short-term treatment protocols by antiestrogens. The pregnancy rate was $15.4 \%$ in the patient group versus $12.5 \%$ in the control group (odds ratio $1.56,95 \%$ CI 0.99 2.19). The authors concluded that there is not enough evidence to support the value of antiestrogens in the management of oligoasthenozoospermia. Nevertheless, they pointed out that the ease of administration, low cost and mild side effects justify their utility despite the minor benefit.

In the Cochrane antiestrogen report the odd's ratio did not reach statistical significance since the 1.00 value is included within the confidence intervals, though with the smallest possible margin (lower limit in Cochrane: 0.99). It is particularly important to take this warning into consideration in case a type II error may be responsible for the lack of evidence of effect. Care should be taken not to interpret 'not enough evidence of effect' as 'evidence of no effect' [6].

The European Association of Urology Guidelines for Antiestrogen Therapy suggested that antiestrogens are potentially effective, and their use must be counterbalanced against possible side effects [11].

Limited studies evaluate the use of antiestrogens in azoospermia. In a case series from three international centers, comprising 42 patients with non-obstructive azoospermia, $64.3 \%$ of patients responded to clomid and produced sperm in the ejaculate, sufficient for ICSI. The study group included cases of maturation arrest (42.9\%) and hypospermatogenesis (57.1\%), and no cases of Sertoli cell-only syndrome. The dose of clomiphene citrate was titrated to achieve a serum testosterone level between 600 and $800 \mathrm{ng} / \mathrm{dl}$. The posttreatment sperm concentration ranged from 1 to 16 million sperm/ml (mean 3.8) [12]. 


\section{Combination Therapy}

Combination therapies have been noted to improve pregnancy rates. Several trials were performed examining the advantages of combination therapy in improving pregnancy rates with or without assisted reproductive techniques. In a randomized RCT by Comhaire et al. [13], 30 men with infertility received treatment in the form of antiestrogens, antibiotics for genital tract infection, or varicocelectomy as indicated, and a strong antioxidant: Astaxanthin $16 \mathrm{mg} /$ day. The total and per cycle pregnancy rates among the placebo cases (10.5 and 3.6\%) were lower compared with 54.5 and $23.1 \%$ respectively in the Astaxanthin group $(\mathrm{p}=0.028, \mathrm{p}=0.036)$. The authors concluded that the results needed to be confirmed in a larger trial.

In a RCT of 212 patients, treatment with tamoxifen citrate and testosterone undecanoate improved sperm variables and led to a higher incidence of pregnancy in couples with subfertility related to idiopathic oligozoospermia. The incidence of pregnancy was $33.9 \%$ in the active treatment group and $10.3 \%$ in the placebo group (36 vs. 11 pregnancies), with a relative risk of 3.195 (95\% CI 2.615-3.765) [13].

On the other hand, the guidelines of the European Association of Urology state that combination therapy of tamoxifen and testosterone undecanoate appear to increase the natural conception rate in a selection of men with idiopathic oligozoospermia [11].

\section{Antioxidant Food Supplements}

The rationale behind the usage of antioxidant supplements in the treatment of male infertility lies in the fact that spermatozoa are very much susceptible to oxidative stress-induced damage. It has been previously reported that men with significant levels of reactive oxygen species (ROS) may very well suffer from low fertility compared with men with lower ROS levels $[14,15]$. In this part of the review we will have a brief overview on the potential role of various antioxidants as therapeutic agents for male infertility.

\section{Glutathione}

Several studies demonstrated that glutathione, the most abundant non-protein thiol in mammalian cells, may emerge in higher levels in fertile than infertile men $[16,17]$. However, there is very little clinical evidence to support the use of glutathione in the medical treatment of male infertility, even as an adjuvant therapy [18].

Evidence-Based Medicine in Male Infertility
Vitamin E

Vitamin $\mathrm{E}$ is another important antioxidant agent that acts as a biological deterrent against the peroxidation of tissue polyunsaturated fatty acids. Its antioxidant activity is similar to that of glutathione peroxidase. Interest in the role of vitamin E in male infertility stemmed from the observation that the percent of motile spermatozoa is significantly related to sperm vitamin E content [19]. Indeed several studies showed a significant increase in sperm motility and function following supplementation with vitamin E [20,21], however they all suffered various methodological errors. In 1999, Rolf et al. [22] demonstrated, in a well-controlled study, that vitamin E supplementation did not improve any semen parameter.

\section{Carnitine}

In addition to possessing antioxidant properties, carnitine can enhance sperm motility through its positive effects on sperm energy production [23]. Two recent welldesigned placebo-controlled studies demonstrated that carnitine and acetylcarnitine can significantly improve sperm motility or kinetics in patients with asthenozoospermia $[24,25]$. However, in the first study the treated group showed an increase in sperm count to only 9 million/ml versus $7.4 \mathrm{million} / \mathrm{ml}$ in controls [24]. Additionally, another criticism of this study is that there was no documented improvement in semen in men who achieved pregnancy $[23,24]$. The study of Balercia et al. [25], while showing a significant increase in sperm motility of patients treated with carnitine or acetylcarnitine, did not observe a corresponding increase in sperm count. Additionally, there was no long-term follow-up of the patients to compare the pregnancy rates between the treated group and the placebo group.

\section{Folic Acid and Zinc}

In a placebo-controlled trial, folic acid and zinc were able to significantly increase sperm concentration and morphology in subfertile men compared with men with normal seminogram [26]. However, there is no available literature to investigate whether administration of these two compounds can lead to increase fertility.

\section{Plant Extracts}

In recent years there has been growing interest in the potential favorable effects of plant extracts on improving sperm quality in patients with subfertility. For example, Roseff and Gulati [27] showed that the oral administration of $200 \mathrm{mg}$ of the extract of the bark of Pinus maritimia can improve sperm morphology by $99 \%$. These ap-

.


Table 1. Available evidence in the medical treatment of male infertility

\begin{tabular}{|c|c|c|c|}
\hline Treatment option & Best available evidence & Study outcome & $\begin{array}{l}\text { Level of evi- } \\
\text { dence ICUD }\end{array}$ \\
\hline Gonadotropin therapy $[2,3]$ & $\begin{array}{l}\text { Systematic review with } \\
\text { meta-analysis }\end{array}$ & $\begin{array}{l}\text { Potentially effective, but more studies are needed } \\
\text { to confirm the findings }\end{array}$ & 1 \\
\hline Antiestrogen therapy [10] & $\begin{array}{l}\text { Systematic review with } \\
\text { meta-analysis }\end{array}$ & $\begin{array}{l}\text { Not enough evidence of effect; low cost and safety } \\
\text { justify its use in selected patients }\end{array}$ & 1 \\
\hline $\begin{array}{l}\text { Antiestrogen therapy in } \\
\text { azoospermia [12] }\end{array}$ & Case series & $\begin{array}{l}\text { Might help produce sperm for ICSI; } \\
\text { RCT are needed }\end{array}$ & 3 \\
\hline $\begin{array}{l}\text { Combination therapy } \\
\text { antiestrogen }+ \text { androgen [14] }\end{array}$ & RCT & $\begin{array}{l}\text { Potentially effective more studies are needed to } \\
\text { confirm the findings }\end{array}$ & 1 \\
\hline $\begin{array}{l}\text { Combination therapy } \\
\text { antiestrogen }+ \text { antioxidants [13] }\end{array}$ & RCT (small numbers) & $\begin{array}{l}\text { Potentially effective more studies are needed to } \\
\text { confirm the findings }\end{array}$ & 2 \\
\hline L-Carnitine $[24,25]$ & RCTs & Improved motility, insufficient pregnancy data & 2 \\
\hline
\end{tabular}

parently dramatic changes have been attributed to the cyclooxygenase isoenzyme 2 inhibitory substances present in these plants. Another extract with similar effects, Lepidium meyenii, resulted in sperm production and motility even in men with normal spermatogenesis $[28,29]$. We think that all these results should be interpreted with caution as none of these trials was placebo-controlled with many methodological errors and results not further verified by other studies.

Table 1 illustrates all the previously mentioned medical treatment options of male infertility and the level of evidence supporting each option.

\section{Methodological Obstacles and Shortcomings of Clinical Trials}

Shortcomings of current research evidence in the field of medical therapy for male infertility are overt, making a final decision in this respect premature. Shortcomings include:

(1) Short-term studies: While we allow newly married couples 1 year to conceive before a diagnosis of infertility is made, we allow an average of 3 months for most trials, giving little chance for conception even if seminal parameters improve. Results of medical treatment in terms of cumulative pregnancy rates may differ if the follow-up period is long enough. For instance, Buvat et al. [30] reported a cumulative pregnancy rate of $41.2 \%$ at 1 year with tamoxifen therapy for infertile couples.
(2) Limited study groups: Many trials conclude with an opinion that requires validation by further studies on different patient groups, and with more patients in each group. The need for large numbers means that such trials almost certainly would have to be organized on a multicenter basis.

(3) Patient selection: Most available studies included patient groups of heterogeneous etiology rather than being restricted to those with idiopathic male infertility with normal-sized testicles and low normal FSH.

(4) Bias generated by the normal variations in semen pattern: The natural unpredictable variations in semen parameters obscure judgment of pre- and posttreatment status. This should be addressed in clinical trials by repeating analyses and taking an average for pre- and posttreatment values.

\section{Ethical Concerns}

It is our obligation to use the (frequently limited) financial resources of our patients in a judicious manner. Therefore, it is mandatory to carefully, and without bias, balance the cost versus efficacy for different treatment modalities. Safety involves husband, wife and child. In the unique situation of male infertility, one party is treated for an illness afflicting both parties. This should be re-evaluated. A well-informed couple should share in the decision-making (respect patient preferences and values). 


\section{Conclusions and Recommendations}

Patients must be informed of all available options and their corresponding pregnancy rates and risks, assessed through RCTs of robust design, and allowed to share in the decision-making. Most current combination therapies consist of orphan medications without industry support. Andrology research centers and other dedicated departments and units need to conduct RCTs of sufficient duration, sample number and robust design for groups most likely to benefit from antiestrogens, L-carnitine, antioxidants, and combination therapy. The ease of administration, low cost and mild side effects of antiestrogens justify their utility despite insufficient evidence of effect as monotherapies. RCTs assessing other forms of medical therapy and combination therapy are available but are still in the preliminary stages.

\section{References}

1 Backett DL, Rosenberg WM, Gray JA, Haynes RB, Richardson WS: Evidence-based medicine: what it is and what it isn't. Clin Orthop Relat Res 2007;455:3-5

2 Attia AM, Al-Inany HG, Proctor ML: Gonadotrophins for idiopathic male factor subfertility. Cochrane Database Syst Rev 2006;1: CD005071.

3 Attia AM, Al-Inany HG, Proctor ML: Gonadotrophins for idiopathic male factor subfertility (update). Cochrane Database Syst Rev 2007;4:CD005071.

-4 Kamischke A, Nieschlag E: Analysis of medical treatment of male infertility. Hum Reprod 1999;14:1-23.

-5 Matorras R, Perez C, Corcostegui B, Pijoan JI, Ramon O, Delgado P, Rodriguez-Escudero FJ: Treatment of the male with follicle-stimulating hormone in intrauterine insemination with husband's spermatozoa: a randomized study. Hum Reprod 1997;12:24-28.

6 Comhaire F, Mahmoud A: The First World Congress on Controversies in Obstetrics, Gynecology and Infertility, Prague, 1999.

-7 Gerris J, Comhaire F, Hellemans P, Peeters K, Schoonajs F: Placebo-controlled trial of highdose mestrolone treatment of idiopathic male infertility. Fertil Steril 1991;55:603-607.

-8 Comhaire F: Treatment of idiopathic testicular failure with high-dose testosterone undecanoate: a double-blind pilot study. Fertil Steril 1990;54:689-693.

9 Comhaire F, Mahmoud A: Hormonal treatment of infertility; in Schill WB, Comhaire F, Hargreave T (eds): Andrology for the Clinician. Berlin, Springer, 1996, pp 516-519.

10 Vandekerckhove P, Lilford R, Vail A, Hughes E: Clomiphene or tamoxifen for idiopathic oligo/asthenospermia. Cochrane Database Syst Rev 2007;4:CD000151. (This paper has been withdrawn from the Cochrane library as it has not been updated since 1996.)

11 Dohle GR, Jungwirth A, Colpi G, Giwercman A, Diemer T, Hargreave TB: European Association of Urology Guidelines for Male Infertility.http://www.uroweb.org/fileadmin/user_ upload/Guidelines/13\%20Male\%20Infertility. pdf (accessed Dec 11, 2007).
2 Hussein A, Ozgok Y, Ross C, Niederberger $\mathrm{L}$ : Clomiphene administration for cases of non-obstructive azoospermia: a multicenter study. J Androl 2005;26:787-791.

13 Comhaire FH, El Garem Y, Mahmoud A, Eertmans F, Schoonjans F: Combined conventional/antioxidant Astaxanthin treatment for male infertility: a double-blind, randomized trial. Asian J Androl 2005;7: 257-262.

$\checkmark 14$ Adamopoulos DA, Pappa A, Billa E, Nicopoulou S, Koukkou E, Michopoulos J: Effectiveness of combined tamoxifen citrate and testosterone undecanoate treatment in men with idiopathic oligozoospermia. Fertil Steril 2003;80:914-920.

5 Sharma RK, Agarwal A: Role of reactive oxygen species in male infertility. Urology 1996 48:835-850.

16 Raijmakers MT, Roelofs HM, Steegers EA, Steegers-Theunissen RRP, Mulder TP, Knapen MF, et al: Glutathione and glutathione S-transferases A1-1 and P1-1 in seminal plasma may play a role in protecting against oxidative damage to spermatozoa. Fertil Steril 2003;79:169-172.

17 Ochsendorf FR, Buhl R, Bastlein A, Beschmann H: Glutathione in spermatozoa and seminal plasma of infertile men. Hum Reprod 1998;13:353-359.

18 Lenzi A, Lombardo F, Gandini L, Culasso F, Dondero F: Glutathione therapy for male infertility. Arch Androl 1992;29:65-68.

19 Therond P, Auger J, Legrand A, Jouannet P: Alpha-tocopherol in human spermatozoa and seminal plasma: relationships with motility, antioxidant enzymes and leukocytes. Mol Hum Reprod 1996;62:739-744.

20 Keskes-Ammar L, Feki-Chakroun N, Rebai T, Sahnoun Z, Ghozzi H, Hammami S, et al: Sperm oxidative stress and the effect of an oral vitamin $\mathrm{E}$ and selenium supplement on semen quality in infertile men. Arch Androl 2003;49:83-94.

21 Kessopoulou E, Powers HJ, Sharma KK, Pearson MJ, Russell JM, Cooke ID, et al: A double-blind, randomized, placebo crossover controlled trial using the antioxidant vitamin $\mathrm{E}$ to treat reactive oxygen species associated male infertility. Fertil Steril 1995; 64:825-831.

-22 Rolf C, Cooper TG, Yeung CH, Nieschlag E: Antioxidant treatment of patients with asthenozoospermia or moderate oligoasthenozoospermia with high-dose vitamin $\mathrm{C}$ and vitamin E: a randomized, placebo-controlled, double-blind study. Hum Reprod 1999; 14:1028-1033.

23 Kumar R, Gautam G, Gupta NP: Drug therapy for idiopathic male infertility: rationale versus evidence. J Urol 2006;176:1307-1312.

24 Lenzi A, Sgrò P, Salacone P, Paoli D, Gilio B, Lombardo F, Santulli M, Agarwal A, Gandini L: A placebo-controlled double-blind randomized trial of the use of combined Lcarnitine and L-acetylcarnitine treatment in men with asthenozoospermia. Fertil Steril 2004;81:1578-1584.

25 Balercia G, Regoli F, Armeni T, Koverech A, Mantero F, Boscaro M: Placebo-controlled, double-blind, randomized trial on the use of L-carnitine, L-acetylcarnitine, or combined L-carnitine and L-acetylcarnitine in men with idiopathic asthenozoospermia. Fertil Steril 2005;84:662-671.

26 Wong WY, Merkus HM, Thomas CM, Menkveld R, Zielhuis GA, Steegers-Theunissen RP: Effects of folic acid and zinc sulfate on male factor subfertility: a doubleblind, randomized, placebo-controlled trial. Fertil Steril 2002;77:491-498.

27 Roseff S, Gulati R: Improvement of sperm quality by Pycnogenol. Eur Bull Drug Res 1999; 7:33-36.

28 Gonzales G, Ruiz A, Gonzales C, Villegas L, Cordova A: Effect of Lepidium meyneii (Maca) roots on spermatogenesis of male rats. Asian J Androl 2001;3:231-233.

29 Gonzales G, Cordova A, Gonzales C, Chung A, Vega K, Villena A: Lepidium meyenii (Maca) improved semen parameters in adult men. Asian J Androl 2001;3:301-303.

30 Buvat J, Buvat-Herbaut M, Marcolin G, Ardaens-Boulier K: Antiestrogens as treatment of female and male infertilities. Horm Res 1987;28:219-229. 